\title{
BMJ Open Persistent SOMAtic symptoms ACROSS diseases - from risk factors to modification: scientific framework and overarching protocol of the interdisciplinary SOMACROSS research unit (RU 5211)
}

\author{
Bernd Löwe (D) , ${ }^{1}$ Viola Andresen, ${ }^{2}$ Omer Van den Bergh, ${ }^{3}$ Tobias B Huber, ${ }^{4}$ \\ Olaf von dem Knesebeck, ${ }^{5}$ Ansgar W Lohse, ${ }^{6}$ Yvonne Nestoriuc, ${ }^{7,8}$ \\ Gudrun Schneider, ${ }^{9}$ Stefan W Schneider, ${ }^{10}$ Christoph Schramm, ${ }^{6,11}$ Sonja Ständer, ${ }^{12}$ \\ Eik Vettorazzi, ${ }^{13}$ Antonia Zapf, ${ }^{13}$ Meike Shedden-Mora, ${ }^{1,14}$ Anne Toussaint ${ }^{1}$
}

To cite: Löwe B, Andresen V, Van den Bergh 0, et al. Persistent SOMAtic symptoms ACROSS diseases - from risk factors to modification: scientific framework and overarching protocol of the interdisciplinary SOMACROSS research unit (RU 5211). BMJ Open 2022;12:e057596. doi:10.1136/ bmjopen-2021-057596

\section{- Prepublication history for} this paper is available online. To view these files, please visit the journal online (http://dx.doi. org/10.1136/bmjopen-2021057596).

MS-M and AT contributed equally.

Received 21 September 2021 Accepted 26 November 2021

Check for updates

(c) Author(s) (or their employer(s)) 2022. Re-use permitted under CC BY-NC. No commercial re-use. See rights and permissions. Published by BMJ.

For numbered affiliations see end of article.

Correspondence to

Professor Bernd Löwe;

b.loewe@uke.de

\section{ABSTRACT}

Introduction Persistent somatic symptoms (PSS) are highly prevalent in all areas of medicine; they are disabling for patients and costly for society. The subjective symptom burden often correlates poorly with the underlying disease severity, and patients' needs for effective treatment are far from being met. Initial evidence indicates that, in addition to disease-specific pathophysiological processes, psychological factors such as expectations, somatosensory amplification and prior illness experiences contribute to symptom persistence in functional as well as in somatic diseases. However, prospective studies investigating the transition from acute to chronic somatic symptoms, integrating pathophysiological, psychological and social factors, are scarce. A better understanding of the multifactorial mechanisms of symptom persistence is crucial for developing targeted mechanism-based interventions for effective prevention and treatment of PSS. Thus, the overall aim of the interdisciplinary SOMACROSS research unit is to identify generic and disease-specific risk factors and aetiological mechanisms of symptom persistence across a range of diseases.

Methods and analysis Seven projects will investigate risk factors and mechanisms of symptom persistence in a total of 3916 patients across 10 medical conditions. All study designs are prospective and share common assessment points, core instruments and outcome variables to allow comparison and validation of results across projects and conditions. Research will focus on the identification of generic and disease-specific mechanisms associated with unfavourable symptom course. The development of a multivariate prediction model will facilitate the understanding of the course of PSS across diseases.

Ethics and dissemination All individual SOMACROSS studies were approved by the ethics committees of the Medical Chambers Hamburg and Münster, Germany. Findings will be disseminated through peer-reviewed
Strengths and limitations of this study

- Although persistent somatic symptoms (PSS) are highly prevalent among various diseases, distressing and disabling for patients and costly for society, mechanisms of symptom persistence are rarely investigated and poorly understood.

- The SOMACROSS research unit goes beyond previous research by determining the complex and dynamic biopsychosocial interplay contributing to persistent symptom states in a number of different syndromes and diseases.

- In order to detect patterns of symptom persistence across diseases, the SOMACROSS research unit aims to identify potential risk factors and mechanisms of PSS across various somatic diseases, functional syndromes and somatoform disorders using a common working model, joint core measures, prospective designs and coordinated evaluation methods.

- The SOMACROSS research unit uses a multidisciplinary approach to overcome today's highly fragmented research on PSS and provide pathways to developing efficient disease-overarching intervention strategies.

- Despite investigating multiple potential risk factors and mechanisms of the persistence of somatic symptoms, other variables might be relevant; and conclusions can only be drawn for the conditions under investigation.

publications, scientific conferences and the involvement of relevant stakeholders, patients and the lay public. This interdisciplinary research unit will fundamentally contribute to earlier recognition of patients at risk, and to the development of prevention and tailored treatment concepts for PSS. 


\section{INTRODUCTION}

\section{State of the art}

Definition: persistent somatic symptoms (PSS)

The term 'persistent somatic symptoms (PSS)' is used as an umbrella term to describe subjectively distressing somatic complaints, irrespective of their aetiology, that are present on most days for at least several months. PSS are operationalised by repeated measures of patients' subjective somatic symptom severity.

\section{PSS across medical fields}

PSS are highly prevalent in all fields of medicine, from primary to specialised care and mental healthcare, ${ }^{12}$ yet remain greatly neglected in research. ${ }^{3}$ Complaints may include pain, gastroenterological, cardiovascular, genitourinary, neurological or other symptoms (figure 1). Regardless of their aetiology, PSS cause substantial suffering, impaired quality of life and work participation. ${ }^{45}$ Many somatic symptoms are neither exclusive correlates of somatic disease (eg, vascular or inflammatory disease) nor exclusive symptoms of a mental disorder (e.g., depressive or anxiety disorders). ${ }^{267}$ Thus, a dualistic view classifying symptoms as either somatic or psychological is neither evidence-based nor patient-centred. ${ }^{8}$ With reference to the description of bodily distress disorder (BDD) in the International Classification of Diseases, 11th edition (ICD-11), the term 'persistent' here defines somatic symptoms which are present on most days for at least several months. ${ }^{9}$

\section{Impact on patients - challenges in healthcare}

Eighty per cent of the general population experience one or more symptoms within 1 month. ${ }^{10-12}$ Somatic symptoms account for the majority of all primary and secondary care consultations. ${ }^{1314}$ Whereas in most cases, symptoms fluctuate naturally and eventually disappear, about one-fourth of individuals with acute symptoms develop PSS and remain affected 1 year after their first consultation. ${ }^{8}$ Often, these symptoms are accompanied by comorbid depression and anxiety ${ }^{2}$ and an increased risk for suicidal ideation and attempts. ${ }^{1516}$ PSS are costly for society, ${ }^{17} 18$ and healthcare for PSS is challenging. ${ }^{19}$ The clinical reality is characterised by fragmented treatment in specialised care (eg, gastrointestinal symptoms in gastroenterology, chest pain in cardiology), even though patients often report multiple or overlapping symptoms. ${ }^{20}$

\section{From 'medically unexplained' to a broader understanding of} distressing PSS

Most research on PSS has been conducted on so called 'medically unexplained symptoms', a term mainly used in primary care, while specialised medical fields more

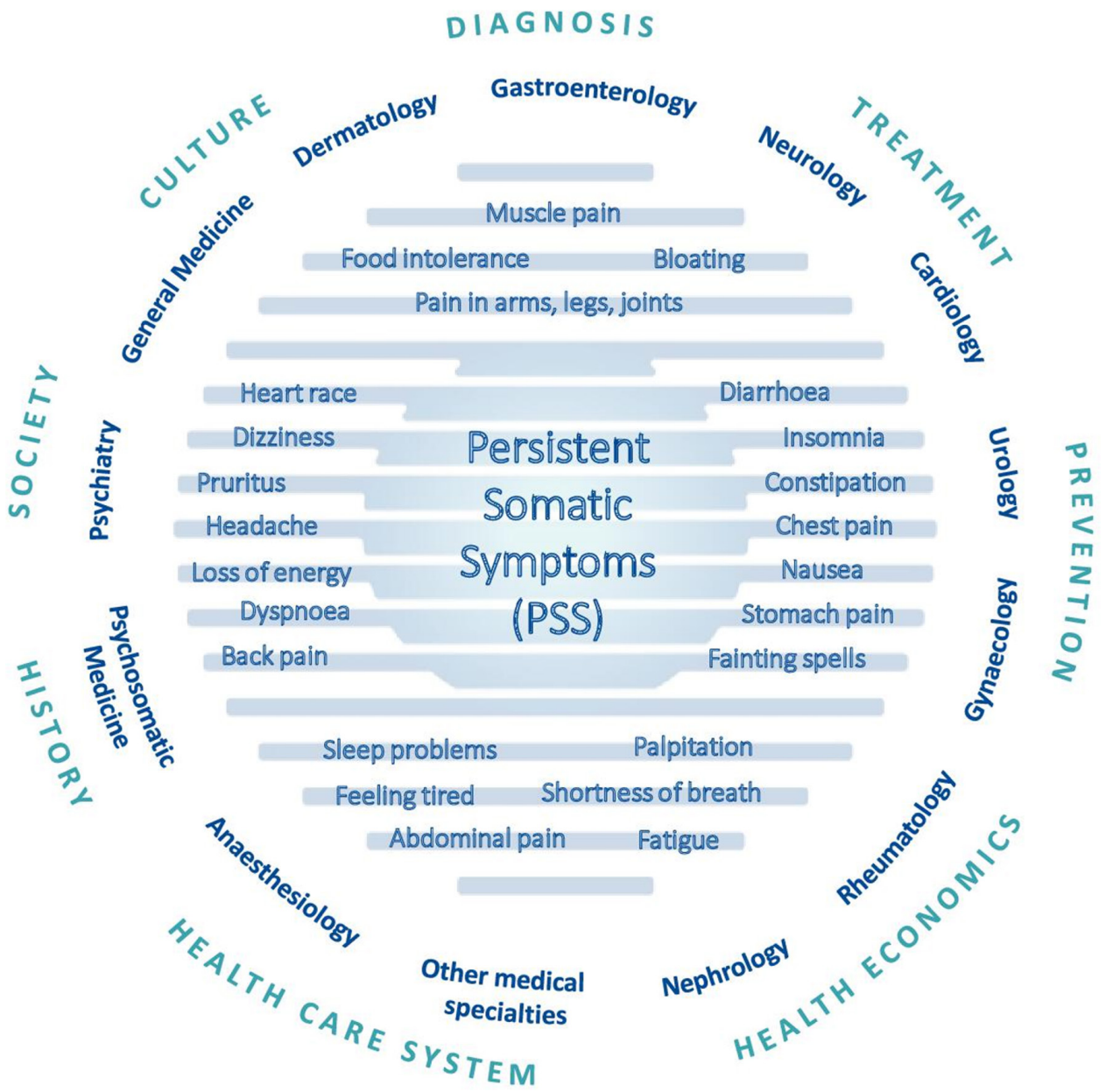

Figure 1 Relevance of persistent somatic symptoms 
commonly employ the term 'functional syndromes'. ${ }^{21}$ The 'medical inexplicability' of the symptoms was also the defining diagnostic criterion of the earlier diagnosis of somatoform and related disorders in the Diagnostic and Statistical Manual for Mental Disorders, 4th edition (DSMIV ${ }^{22}$ and the International Classification of Diseases, 10th edition (ICD-10) ${ }^{23}$ The concept of medical inexplicability of somatic symptoms is considered problematic because (1) the label 'medically unexplained' for disabling symptoms creates distress in patients, ${ }^{24}$ (2) the reliability of assessing whether or not there is a pathophysiological explanation for a certain symptom is notoriously poor, (3) the concept reinforces a mind-body dualism ${ }^{8}$ and (4) many patients disapproved of the term. ${ }^{25}$ Therefore, a new conceptualisation was introduced namely somatic symptom disorder (SSD) in DSM- $5{ }^{26}$ and BDD in ICD- $10,{ }^{9}$ incorporating features of persistent and clinically significant somatic complaints which are accompanied by excessive and disproportionate healthrelated concerns, feelings and behaviours. SSD and BDD may or may not be accompanied by a somatic disease. ${ }^{27}$ Of note, patients with 'medically explained' and 'unexplained' symptoms are equally impaired. ${ }^{45}$

\section{Transferability of psychosocial aetiological mechanisms from functional and somatoform disorders to somatic diseases}

Most research on aetiological mechanisms of PSS has been conducted in somatoform and functional syndromes. The question arises whether these findings can be transferred to SSD and BDD, and beyond that, to PSS in somatic diseases. There is initial evidence that - in addition to the underlying pathophysiology - psychosocial factors play a relevant role in the development and persistence of symptoms in somatic diseases. For example, previous studies by our group indicated that patients' beliefs about their disease strongly influence recovery after coronary artery bypass surgery, ${ }^{28}$ that pre-treatment expectations significantly predict patientreported long-term side-effects and quality of life in women receiving endocrine breast cancer treatment, ${ }^{29}$ and that the extent of illness anxiety before gastrointestinal infection predicts the development of post-infectious irritable bowel syndrome after 7 months. ${ }^{30}$ The understanding of psychosocial factors, in turn, can help improve treatment for patients with PSS. First evidence in support of this is available from the PSY-HEART trial, a three-arm randomised clinical trial in which a preoperative optimisation of patient expectations prior to coronary artery bypass graft surgery led to a reduction of postoperative disability compared with usual surgery care alone. $^{31}$

Even though it remains unclear how PSS evolve and are maintained over time, their presence in various somatic diseases is associated with a faster disease progression, more severe complications and increased mortality. ${ }^{32-34}$ Further evidence supporting the important role of psychosocial factors in the persistence of symptoms in somatic diseases is provided by the observation that symptom burden frequently persists although the underlying pathophysiology has been optimally treated. ${ }^{55}$ In addition to disease-specific treatment, psychological treatment and centrally acting pharmacotherapy appear to be the most promising options, not only for functional and somatoform disorders but also for PSS in well-defined somatic diseases. ${ }^{19}$ This suggests that generic, trans-diagnostic treatment principles ${ }^{36}$ may be valuable in addition to the disease-specific treatment of the underlying pathophysiology. Across somatic diseases, a diverse array of psychological and social factors needs to be considered on equal footing with biological factors in their roles as potential risk factors, protective factors and maintaining factors of PSS. Importantly, psychological and social factors are not solely secondary reactions to persistent symptoms; rather, they are deeply woven into the biopsychosocial processes that lead to PSS.

To conclude, sufficient evidence warrants the assumption that aetiological mechanisms derived from research on somatoform and functional disorders also contribute to the persistence of symptoms in somatic diseases. However, the applicability of generic and specific risk factors and mechanisms of PSS across medical diseases has yet to be investigated.

\section{Definitions: risk factors and aetiological mechanisms}

'Risk factors' refer to variables associated with an increased risk of symptom persistence, although the relationship is not necessarily causal. 'Aetiological mechanisms' denote underlying mechanisms which are presumed to be causally involved in the persistence of symptoms.

\section{Current aetiological knowledge on PSS}

The aetiology of PSS across somatic diseases is not well understood. The unique way in which each individual perceives a somatic symptom and its severity, the expectation on how the symptom will evolve, and whether the treatment will be effective depends on the constellation of biological, psychological and social factors. The comprehensive vulnerability-stress model by Henningsen et al. ${ }^{19}$ defines predisposing, triggering and maintaining/aggravating factors that determine the transition from shortterm to persistent disabling symptoms. After extensively reviewing the literature for all targeted conditions included in the SOMACROSS research unit (RU), we developed a 'PSS working model' as a starting point for the investigation of disease-overarching generic and disease-specific risk factors and aetiological mechanisms (see figure 2). The risk factors and aetiological mechanisms described below are considered most relevant to PSS.

a. Predisposing factors: Predisposing factors for PSS include sociodemographic risk factors such as female gender, ${ }^{37}$ poor education and socioeconomic status, ${ }^{3}{ }^{38}$ sociocultural factors, ${ }^{39}$ psychological aspects such as early adverse life experiences, ${ }^{40-43}$ personality factors like neuroticism and negative affectivity, ${ }^{44}$ biomedical factors such as prior medical diseases, ${ }^{44}$ certain (epi)genetic profiles ${ }^{45}$ and immunological correlates of these factors. ${ }^{34647}$

b. Triggering factors: Triggering factors for short-term somatic symptoms include acute infections, injuries, medical or surgical procedures or current life stressors. $^{19} 30$ 


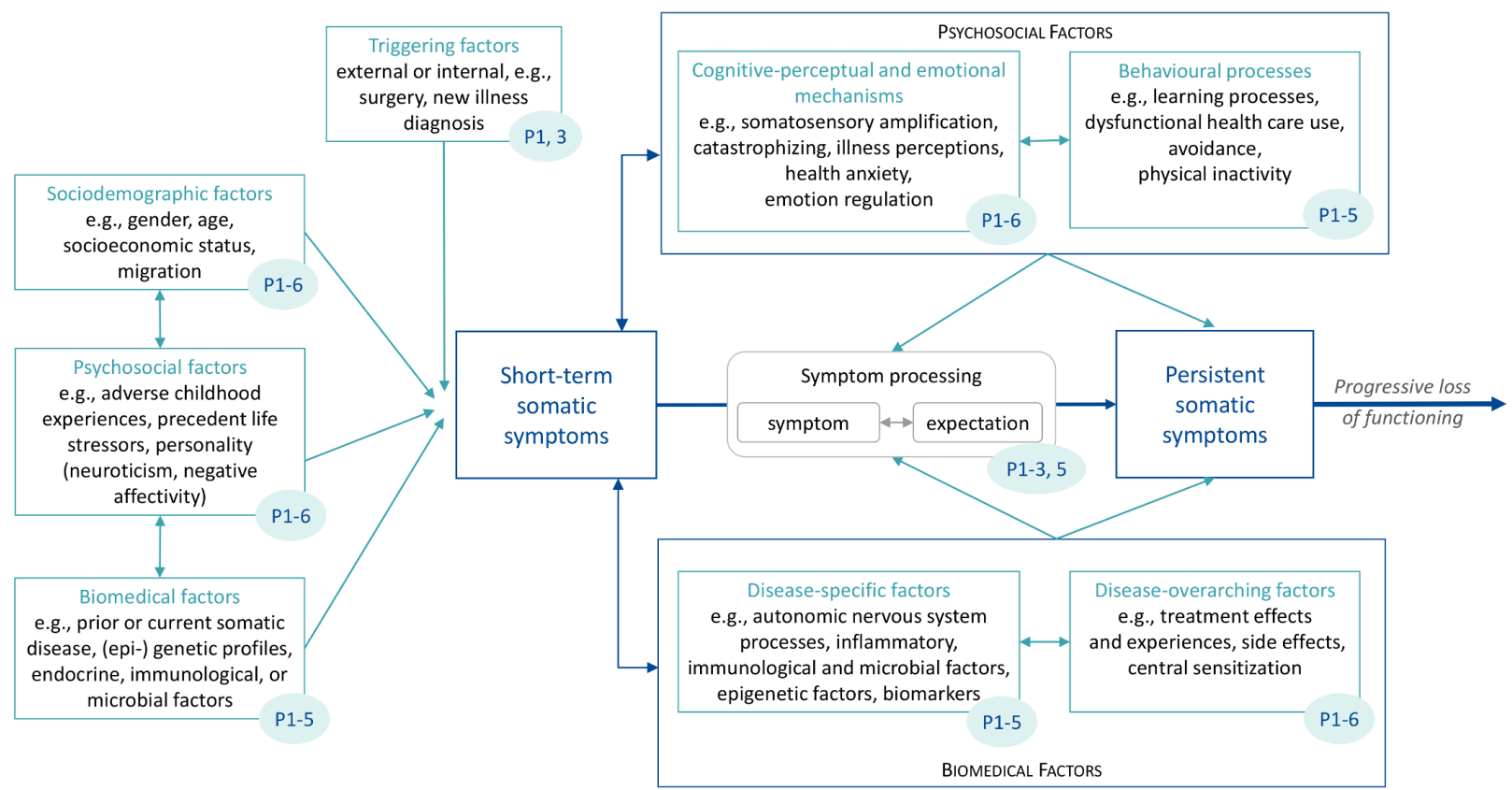

Figure 2 Working model of the SOMACROSS research unit: risk factors and mechanisms for somatic symptom persistence as investigated by the individual projects (blue numbers indicate projects investigating the respective factors)

c. Maintaining/aggravating factors: Most aetiological models on bodily complaints in somatoform and functional disorders ${ }^{48-50}$ include the following core cognitive-perceptual and emotional mechanisms: selective attention towards interoceptive cues, amplified perception of bodily sensations, catastrophising cognitive interpretations, somatosensory amplification ${ }^{51}$ and dysfunctional illness behaviours. ${ }^{194652}$ Affective factors such as alexithymia comprise deficits in the regulation of emotions. ${ }^{53}$ On the level of dysfunctional behavioural processes, somatic symptoms are aggravated by learning processes, avoidance behaviour such as physical inactivity and subsequent deconditioning. ${ }^{54-56}$ Further aggravating factors arise from unsatisfying encounters with the healthcare system, negative illness perceptions and treatment experiences which result in the unnecessary and potentially harmful overuse of healthcare. ${ }^{19}$ Social factors like work status, health literacy, access to medical care, stigmatisation, migration and culture can be both predisposing and maintaining/aggravating factors of PSS. ${ }^{57}$ Disease-specific biomedical factors (eg, inflammation in inflammatory bowel disease) naturally influence the course of somatic symptom severity. ${ }^{58}$ Additionally, disease-overarching psychobiological models postulate dysregulations of the endocrine, immune and autonomic nervous systems as well as central sensitisation to be potential links between psychosocial distress and PSS. ${ }^{48} 59$ Other biopsychosocial interactions contributing to symptom persistence include treatment-related factors such as burdensome side effects of a treatment for an underlying disease. These side effects are difficult to disentangle from general bodily distress and likely to be influenced by nocebo effects through patients' negative expectations and other psychological factors. ${ }^{60}$ Central sensitisation, defined as hyperexcitability of the central nervous system, has been suggested to contribute to the development and maintenance of chronic pain, while its role in other PSS is under debate. ${ }^{61}{ }^{62}$ Central sensitisation is thought to be driven by neuroinflammation in the central and peripheral nervous system, as indicated by higher serum levels of interleukin 6 (IL-6) and tumour necrosis factor (TNF) ${ }^{61}$ Recently, epigenetic modifications such as DNA methylation have been identified as potential contributors to altered resilience to environmental stress, pain and somatic symptom burden. ${ }^{38} 63$ Stool microbiota alterations are also hypothesised to be associated with the persistence of somatic symptoms. There is evidence of gut microbiota dysbiosis in patients with chronic fatigue and nonvisceral pain. ${ }^{64} 65$

d. Interactions of biopsychosocial factors: Recently, patients' expectations of symptoms have come into focus as having a central role in symptom processing and the relation between biological, psychosocial and treatment-related factors for persistent symptom development. Expectations are defined as future-directed cognitions regarding the anticipated course of symptoms. ${ }^{66}$ As such, they constitute a common denominator of many psychological risk factors for PSS such as catastrophising, illness perceptions and health anxiety. Thus, they can be regarded as a core feature of current aetiological models for PSS (eg, somatosensory amplification). ${ }^{46}$ Negative symptom expectations interact with actual somatic input and can fuel dysfunctional 
signal processing and the development of persistent symptoms. Relevantly, the power of expectations to predict symptom course, treatment benefit and negative treatment side effects has been demonstrated for a wide range of medical and psychological conditions, for example, pain, rheumatoid arthritis, cancer, 'medically unexplained symptoms' and level of functioning after total hip and knee replacements. ${ }^{29}{ }^{67-71}$ Moreover, a growing body of research provides evidence that modifying expectations improves clinical outcomes. ${ }^{31} 7273$

Expectations are also prominently conceptualised in emerging predictive processing models which suggest that symptom perception emerges through an integrative process of sensory input, prior experience (leading to implicit expectations, or 'priors') and contextual cues (such as affective state). ${ }^{74}$ These models show that the relationship between subjective symptoms and pathophysiological dysfunction is highly variable, both between and within individuals, and that pathophysiological dysfunction may even be completely absent in the presence of strong priors and ambiguous somatic input. Depending on relative strength and precision, the actual symptom experience may be more determined by somatic input or by priors.

Altogether, the above-mentioned risk factors and mechanisms of somatic symptom persistence are less well studied in somatic diseases than in functional and somatoform disorders. ${ }^{46}$ We assume that - in addition to disease-specific pathophysiological mechanisms - the processes underlying somatic symptom persistence in somatic diseases and in functional/somatoform disorders involve similar risk factors and mechanisms, opening new routes to modify symptom persistence in somatic diseases.

\section{Novelty and innovation}

SOMACROSS takes on a fundamentally new perspective, by including two new ways of thinking in medicine: first, the abandonment of the concept of medical inexplicability in the diagnostic concepts of functional and somatoform disorders; and second, the shift away from the idea that subjective suffering can essentially be explained by the extent of the underlying physiological pathology. Assuming that biological markers alone do not sufficiently explain aetiology and development of PSS, we will investigate the interaction of biological, psychological and social factors regarding their contribution to subjective symptom severity and symptom persistence in 10 different medical conditions. In this way, SOMACROSS will critically challenge the still prevalent dualistic mindbody disease model in medicine. The use of a transsymptomatic and trans-diagnostic approach will enable the identification of patterns, risk factors and aetiological mechanisms of symptom persistence across diseases and syndromes.

\section{Objectives of the overall project}

The superordinate aim of this interdisciplinary RU is to identify risk factors and mechanisms for the persistence of somatic symptoms across diseases, and thereby create a basis for evidence-based interventions for patients suffering from PSS.

The research objectives of SOMACROSS are:

a. To identify generic (ie, disease-overarching) biological, psychological and social mechanisms contributing to the persistence of somatic symptoms across a range of medical diseases and syndromes.

b. To identify disease-specific mechanisms contributing to the persistence of somatic symptoms.

c. To formulate new, empirically testable hypotheses about the interaction of generic and disease-specific factors and to integrate the derived risk factors and mechanisms into comprehensive prediction models for PSS.

d. To derive generic and disease-specific clinically useful risk factors for symptom persistence.

e. To identify modifiable risk factors and mechanisms in the transition from acute to chronic symptoms.

f. To test whether the therapeutic optimisation of modifiable risk factors (eg, dysfunctional symptom expectations) improves clinical outcomes.

The structural objectives of SOMACROSS are:

a. To raise awareness for a highly relevant research field across medical disciplines.

b. To disseminate knowledge regarding the development and treatment of PSS.

c. To build a strong interdisciplinary research structure focused on PSS.

d. To establish qualifications of the next generation of scientific experts in this field.

\section{Working hypotheses of the overall project}

Hypothesis 1: In all syndromes and diseases examined in SOMACROSS, biological, psychological and social factors contribute to the persistence of somatic symptoms individually or/and in interplay.

Hypothesis 2: Persistence of somatic symptoms is predicted by common risk factors across syndromes and diseases.

Hypothesis 3: Generic and syndrome-specific and/or disease-specific risk scores accurately predict the risk of persistence of somatic symptoms.

Hypothesis 4: Expectations play a relevant role in the development of PSS. Thus, the modification of dysfunctional expectations constitutes a promising starting point for interventions to improve symptom severity in PSS.

\section{METHODS AND ANALYSIS \\ Design}

Investigated symptoms and composition of SOMACROSS

To ensure clinical relevance, symptoms with high prevalence in medical settings were chosen, that is, fatigue, gastrointestinal symptoms, pruritus and multiple co-existing symptoms. ${ }^{75}$ To detect patterns, similarities and discrepancies in symptom persistence across a range of medical conditions, syndromes typically classified as 


\section{Table 1 Individual projects and project leaders of the SOMACROSS research unit}

\begin{tabular}{|c|c|c|c|c|}
\hline $\begin{array}{l}\text { Project } \\
\text { No. }\end{array}$ & Project title & Project content & Project leader(s) & Institution(s) \\
\hline \multirow{2}{*}{$\stackrel{P 1}{=2}$} & \multirow{2}{*}{$\begin{array}{l}\text { Fatigue in primary biliary } \\
\text { cholangitis: factors } \\
\text { associated with severity } \\
\text { and persistence as future } \\
\text { therapeutic targets }\end{array}$} & \multirow{2}{*}{$\begin{array}{l}\text { P1 examines the disease-specific biological } \\
\text { and generic psychosocial factors which } \\
\text { contribute to fatigue in patients with } \\
\text { primary biliary cholangitis and primary } \\
\text { sclerosing cholangitis and aims to } \\
\text { determine its course over time. }\end{array}$} & $\begin{array}{l}\text { Dr. Anne Toussaint, } \\
\text { PhD }\end{array}$ & $\begin{array}{l}\text { Department of } \\
\text { Psychosomatic Medicine } \\
\text { and Psychotherapy, UKE }\end{array}$ \\
\hline & & & $\begin{array}{l}\text { Professor Dr. } \\
\text { Christoph Schramm, } \\
\text { MD }\end{array}$ & $\begin{array}{l}\text { Martin Zeitz Centre for } \\
\text { Rare Diseases and I. } \\
\text { Department of Medicine, } \\
\text { UKE }\end{array}$ \\
\hline \multirow{2}{*}{ 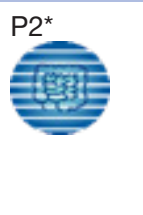 } & \multirow{2}{*}{$\begin{array}{l}\text { Persistence of } \\
\text { gastrointestinal symptoms } \\
\text { in irritable bowel } \\
\text { syndrome and ulcerative } \\
\text { colitis: from risk factors to } \\
\text { modification }\end{array}$} & \multirow{2}{*}{$\begin{array}{l}\text { P2 investigates whether somatic symptoms } \\
\text { in patients with irritable bowel syndrome } \\
\text { and ulcerative colitis are influenced by } \\
\text { illness anxiety and symptom expectations } \\
\text { and could therefore be improved by } \\
\text { expectation management. }\end{array}$} & $\begin{array}{l}\text { Professor Dr. Bernd } \\
\text { Löwe, MD }\end{array}$ & $\begin{array}{l}\text { Department of } \\
\text { Psychosomatic Medicine } \\
\text { and Psychotherapy, UKE }\end{array}$ \\
\hline & & & $\begin{array}{l}\text { Professor Dr. Ansgar } \\
\text { W. Lohse, MD }\end{array}$ & $\begin{array}{l}\text { I. Department of } \\
\text { Medicine, UKE }\end{array}$ \\
\hline \multirow[t]{2}{*}{$\stackrel{P 3}{=-8}$} & \multirow[t]{2}{*}{$\begin{array}{l}\text { Predictors of somatic } \\
\text { symptom persistence } \\
\text { in patients with chronic } \\
\text { kidney disease }\end{array}$} & \multirow[t]{2}{*}{$\begin{array}{l}\text { P3 aims to identify multivariate predictors } \\
\text { of PSS in patients with pre-dialysis chronic } \\
\text { kidney disease (CKD) by testing biomedical, } \\
\text { psychological, and treatment-related } \\
\text { predictors using a mixed methods cohort } \\
\text { study. }\end{array}$} & $\begin{array}{l}\text { Professor Dr. Meike } \\
\text { Shedden-Mora, PhD }\end{array}$ & $\begin{array}{l}\text { Department of } \\
\text { Psychosomatic Medicine } \\
\text { and Psychotherapy, } \\
\text { UKE; Department of } \\
\text { Psychology, Medical } \\
\text { School Hamburg }\end{array}$ \\
\hline & & & $\begin{array}{l}\text { Professor Dr. Tobias } \\
\text { B. Huber, MD }\end{array}$ & $\begin{array}{l}\text { III. Department of } \\
\text { Medicine, UKE }\end{array}$ \\
\hline \multirow{3}{*}{$\stackrel{P 4}{=}$} & \multirow{3}{*}{$\begin{array}{l}\text { Biological and } \\
\text { psychosocial factors } \\
\text { affecting the persistence } \\
\text { of pruritus symptoms }\end{array}$} & \multirow{3}{*}{$\begin{array}{l}\text { P4 examines the interplay of psychosocial } \\
\text { and biological factors affecting the } \\
\text { maintenance of pruritus in patients with } \\
\text { atopic dermatitis, patients with pruritus on } \\
\text { non-lesional skin and healthy controls. }\end{array}$} & $\begin{array}{l}\text { Professor Dr. Stefan } \\
\text { W. Schneider, MD }\end{array}$ & $\begin{array}{l}\text { Department of } \\
\text { Dermatology and } \\
\text { Venerology, UKE }\end{array}$ \\
\hline & & & $\begin{array}{l}\text { Professor Dr. Sonja } \\
\text { Ständer. MD }\end{array}$ & $\begin{array}{l}\text { Department of } \\
\text { Dermatology, University } \\
\text { of Münster }\end{array}$ \\
\hline & & & $\begin{array}{l}\text { Professor Dr. Gudrun } \\
\text { Schneider, MD }\end{array}$ & $\begin{array}{l}\text { Department of } \\
\text { Psychosomatic Medicine } \\
\text { and Psychotherapy, } \\
\text { University of Münster }\end{array}$ \\
\hline \multirow[t]{2}{*}{$\stackrel{\mathrm{P5}^{*}}{\stackrel{=}{=}}$} & \multirow[t]{2}{*}{$\begin{array}{l}\text { Modifiable factors } \\
\text { for somatic symptom } \\
\text { persistence in patients } \\
\text { with somatic symptom } \\
\text { Disorder }\end{array}$} & \multirow{2}{*}{$\begin{array}{l}\text { P5 examines whether expectations } \\
\text { about symptom severity and coping with } \\
\text { symptoms determine symptom persistence } \\
\text { in patients with somatic symptom disorder } \\
\text { in interaction with somatic comorbidity and } \\
\text { psychosocial factors. }\end{array}$} & $\begin{array}{l}\text { Professor Dr. Yvonne } \\
\text { Nestoriuc, PhD }\end{array}$ & $\begin{array}{l}\text { Department of Clinical } \\
\text { Psychology, Helmut- } \\
\text { Schmidt University, } \\
\text { Hamburg }\end{array}$ \\
\hline & & & $\begin{array}{l}\text { Dr. Anne Toussaint, } \\
\text { PhD }\end{array}$ & $\begin{array}{l}\text { Department of } \\
\text { Psychosomatic Medicine } \\
\text { and Psychotherapy, UKE }\end{array}$ \\
\hline & $\begin{array}{l}\text { Social inequalities in } \\
\text { aggravating factors } \\
\text { of persistent somatic } \\
\text { symptoms }\end{array}$ & $\begin{array}{l}\text { P6 examines whether socioeconomic and } \\
\text { migration status are associated with risk } \\
\text { factors for the persistence of irritable bowel } \\
\text { syndrome and fatigue. }\end{array}$ & $\begin{array}{l}\text { Professor Dr. Olaf } \\
\text { von dem Knesebeck, } \\
\text { PhD }\end{array}$ & $\begin{array}{l}\text { Institute of Medical } \\
\text { Sociology, UKE }\end{array}$ \\
\hline$\stackrel{\text { Z-project* }}{\underline{Z}}$ & $\begin{array}{l}\text { Generic and disease- } \\
\text { specific mechanisms } \\
\text { of somatic symptom } \\
\text { persistence across } \\
\text { diseases }\end{array}$ & $\begin{array}{l}\text { The Z-project will oversee the other } \\
\text { projects with respect to adherence to the } \\
\text { common methodology. The Z-project will } \\
\text { pool data from the individual projects to } \\
\text { identify networks of interacting symptoms } \\
\text { and mechanisms of symptom persistence } \\
\text { across projects and diseases. }\end{array}$ & $\begin{array}{l}\text { Professor Dr. Antonia } \\
\text { Zapf, PhD }\end{array}$ & $\begin{array}{l}\text { Department of } \\
\text { Medical Biometry and } \\
\text { Epidemiology, UKE }\end{array}$ \\
\hline
\end{tabular}

${ }^{*}$ Co-applicants: P2: PD Dr. Viola Andresen, MD; Professor Dr. Yvonne Nestoriuc, PhD; P6 and Z-Project: Professor Dr. Bernd Löwe, MD; UKE, Universitätsklinikum Hamburg-Eppendorf (University Medical Centre Hamburg-Eppendorf, Hamburg, Germany).

somatic (eg, primary biliary cholangitis, ulcerative colitis) and syndromes considered as 'functional' or 'somatoform' (eg, irritable bowel syndrome, SSD) were included. The seven projects of SOMACROSS including content and project leaders are listed in table 1.

Each project will investigate specific predisposing, triggering, maintaining or aggravating factors for PSS based on the current state of knowledge in the respective disease or syndrome. Based on our extensive literature review, we compiled a 'PSS working model' (figure 2), which serves as a starting point for rigorous testing of distinct factors with regard to their relevance for symptom persistence across all projects. These factors are assessed by the joint core set of measures (see below) that will be used across all projects. 
Knowledge:

Aimed scientific insight:

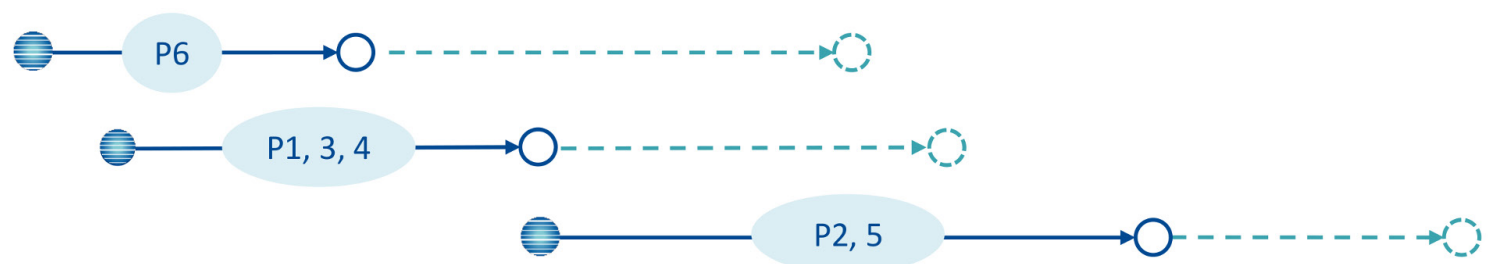

Z-Project

aims for $1^{\text {st }} \mathbf{4}$ year period

$\rightarrow$ (-) aims for $2^{\text {nd }} 4$ year period

Figure 3 Projects 1-6 (P1-6): from current state of knowledge to aims of scientific insight

Other predictor variables, which are considered specific for defined diseases or syndromes only, will be tested in the respective individual projects. Of note, the classification of variables as predisposing, triggering, maintaining and aggravating factors is preliminary and not always distinct.

\section{Study designs and methodological approaches}

The initial state of knowledge varies between the individual projects and health conditions. For some diseases, there is cross-sectional evidence on associations between symptom persistence and specific biopsychosocial variables. For others, longitudinal studies have identified relevant predictors for symptom maintenance. These different starting points in terms of current knowledge lead to different research aims (figure 3). In an envisaged second phase, all projects will take a step towards modification of the relevant factors based on their individual project results.

\section{Shared inclusion and exclusion criteria}

All projects share common basic inclusion criteria, that is, age $\geq 18$ years, sufficient oral and written German language proficiency and written informed consent. Common exclusion criteria include: serious illness requiring immediate intervention; florid psychosis or substance abuse disorder and acute suicidality. In addition to these common criteria, the individual projects defined project-specific inclusion and exclusion criteria.

\section{Shared assessment points}

In order to compare results across projects, all projects (P) with prospective study designs (P1-5) will use identical assessment points, that is, baseline, 6-month and 12-month follow-up. These enable the statistical evaluation of generic predictors across diseases and the pooling of data.

\section{Patient and public involvement}

Involvement of patients or members of the public varies among the projects of the research unit and is therefore described in detail in the study protocols of the individual projects.

\section{Measures}

\section{Shared outcome measures}

Severity of somatic symptoms is the primary outcome for all projects (table 2). Given that (a) somatic symptom severity must be specifically assessed for each symptom, and that (b) generic instruments are needed to conduct comparisons and joint evaluations across projects, somatic symptoms are measured in two ways:

a. Symptom-specific assessment, using specific measures of somatic symptom severity,

b. Generic assessment of overall symptom severity, using the internationally well-established Patient Health Questionnaire-15 (PHQ-15) ${ }^{76} 77$ and the Numeric Rating Scale for symptom intensity as recommended by the EURONET-SOMA group. ${ }^{78}$

Additional shared secondary outcomes include symptom interference, disability and quality of life.

\section{Joint psychosocial core instruments}

The list of joint core instruments of SOMACROSS (table 2) reflects the factors displayed in the PSS working model (figure 2). All joint core instruments were chosen after considering construct relevance, reliability, validity, feasibility, acceptability, availability in German and statistical constraints. In order to assess the comorbidity with DSM-5 SSD in all the diseases investigated, the relevant section of a German research version of the Structured Diagnostic Interview for Mental Disorders (SCID-5) will be conducted. ${ }^{79} 80$

\section{Joint biomedical factors}

In addition to the joint core set of instruments, the various projects of SOMACROSS investigate further common variables with regard to their relevance for PSS. Disease overarching factors such as duration and subjective severity of disease, (prior) biomedical disease and comorbidities, and side effects and subjective treatment experiences will be assessed as potential generic predictors of symptom persistence across all projects. Serum levels of C-reactive protein (CRP), interleukin-6 (IL-6) and tumour necrosis factor (TNF) will be measured at 


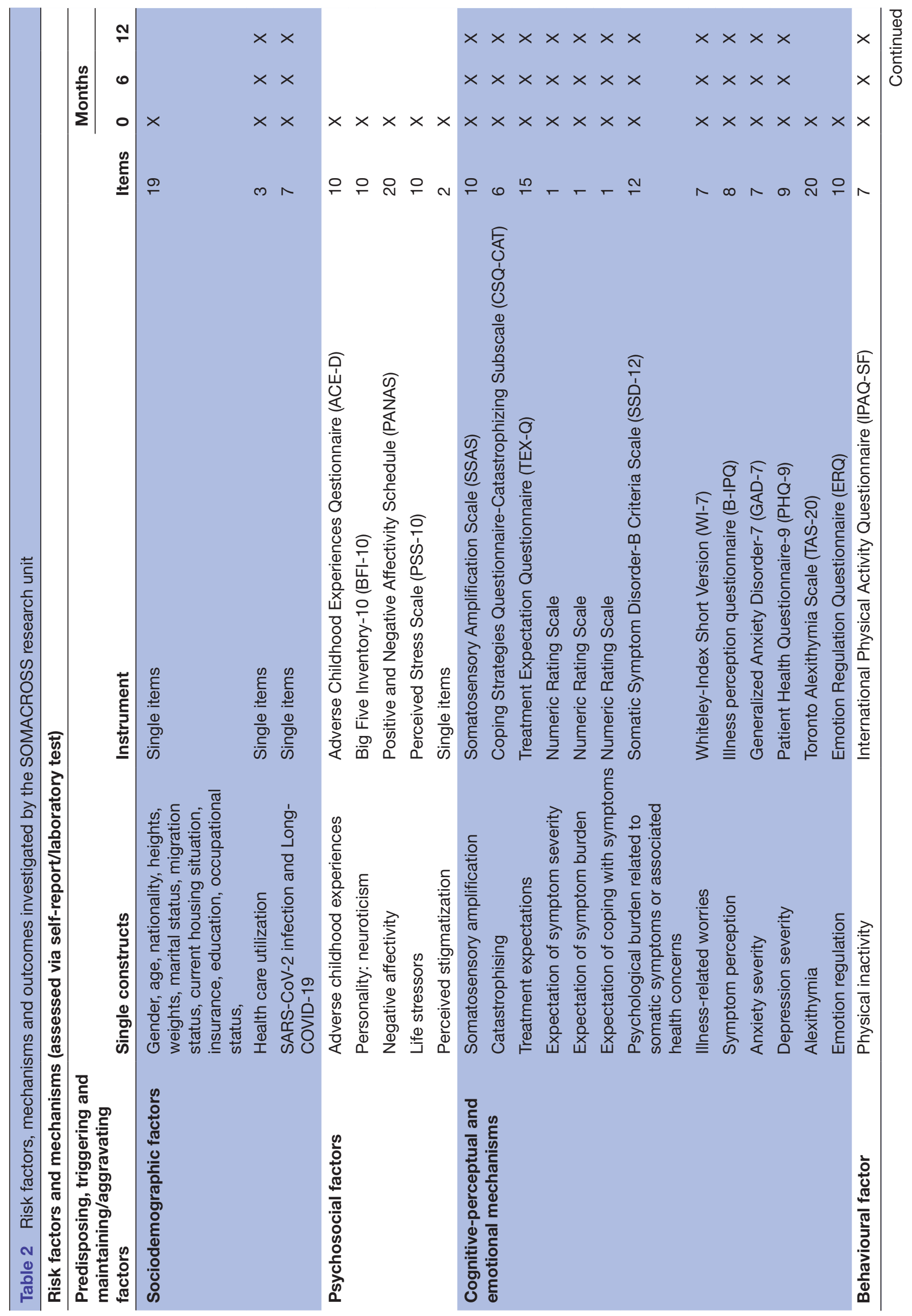




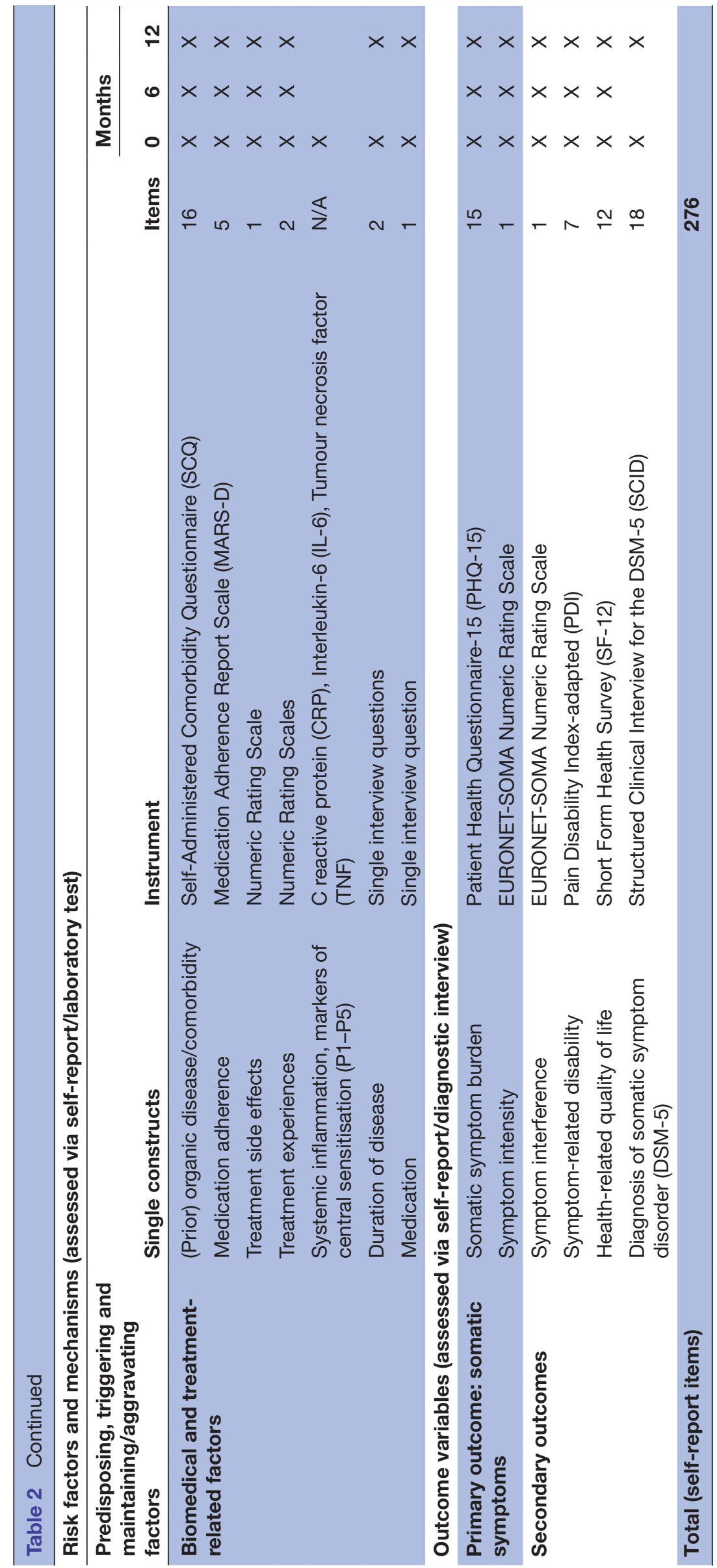


baseline as systemic biomarkers of central sensitisation ${ }^{81}$ to shed light on the controversial role of central sensitisation in the persistence of somatic symptoms both prospectively and in a cross-sectional view across P1-P5. The contribution of epigenetic mechanisms (altered DNA methylation in an epigenome-wide association study) in the course from acute to persistent symptoms in kidney disease will be analysed in P3. Additionally, epigenetic mechanisms will be analysed and cross-validated in pilot samples across P1-P5 ( $\mathrm{n}=20$ patients per diagnosis, $\mathrm{n}=10$ with low vs high baseline symptom burden according to the PHQ-15), led by P3. We will also investigate the role of microbiome alterations for fatigue persistence among patients with primary biliary cholangitis and patients with primary sclerosing cholangitis (P1). In P2 and P3, we will collect stool samples from participants at baseline (P2 also post-intervention). Depending on the results regarding the course of PSS (P2 and P3) and the response to the intervention (P2), we will then analyse the microbiome (metagenomic sequencing). We believe that the abovementioned biomedical factors are potentially relevant across several symptoms and diseases. Further diseasespecific biomedical predictors such as disease stage and disease-specific markers of symptom persistence will be assessed within the individual projects, using appropriate methodology.

\section{Statistical evaluation}

\section{Joint statistical evaluation strategy}

The use of shared measures and assessment points across P1-P6 enables collective statistical analyses ( $\mathrm{n}=1328$ participants; not included are the $\mathrm{n}=2432$ participants from the cross-sectional analysis in $\mathrm{P} 6$ and the $\mathrm{n}=156$ participants of the intervention groups in P2). The power calculations were performed individually for each project and are included in the projects' study protocols. The joint cross-project evaluation will allow us to develop an overarching conceptual model for the persistence of somatic symptoms. We will test paths and associations between the key factors of the working model by using an exploratory approach and initial hypotheses testing. Given scarcity of data on PSS for most of our included diseases and syndromes, we included a large number of variables in the first funding phase. This will enable us to generate new hypotheses for rigorous testing in the future. P1 and P3 will use multimethod approaches by embedding qualitative and experimental studies. Both approaches represent a valuable possibility for an in-depth exploration of mechanisms of symptom perception, development and maintenance. The statistical evaluation across projects will be carried out by biostatistics experts using a structural equation model approach. The statistical analyses will also lead to a reduction in predictors of symptom persistence by removing irrelevant pathways, which will allow more distinct analyses in subsequent studies. Depending on the existing evidence for each condition, some of the projects follow a hypothesis-generating design while others perform confirmatory tests based on prior research (see also figure 3). In exploratory analyses, we do not adjust for multiple testing in order to avoid the loss of power. However, we formulated testable, prespecified initial hypotheses for each project as starting points, which contribute to the overarching hypotheses of the Z-project. Statistical methods to adjust for multiple testing will be applied for the confirmatory analyses.

\section{ETHICS AND DISSEMINATION Ethical approval}

All studies including patients (P1-P6) were approved by the respective Ethics Committees of the Medical Associations Hamburg and Westphalia-Lippe/Westphalian Wilhelms University, Münster, Germany. The individual studies will be conducted in accordance with the WMA Declaration of Helsinki, guidelines for Good Clinical Practice, national and local laws. Eligible patients will be informed about the study verbally and in written form before providing written informed consent.

\section{Data sharing}

De-identified individual patient data will be made publicly available. The times and the conditions of the availability of data will be in accordance with the Recommendations for Sharing Clinical Trial Data' of the Institute of Medicine (IOM). The main findings of each project will be published in peer-reviewed journals and made publicly available. In addition, we will communicate scientific results in lay language via press releases, social media, and patient forums.

\section{Impact and relevance}

Regarding the impact on the research field of PSS, SOMACROSS will provide the urgently needed infrastructure to facilitate collaboration and knowledge exchange between medical disciplines. The research field of PSS will benefit from the measurement of larger sets of predisposing, triggering and maintaining biopsychosocial variables, and from additional theoretical work on their interrelation. By providing information to the public, for example, at a 'patient day' and the SOMACROSS webpage, we hope to improve the understanding of PSS, avoid unnecessary and potentially harming medical procedures and provide reliable information for patients' personalised decisionmaking. Greater awareness and understanding of PSS in society might also lead to reduced stigma associated with PSS. SOMACROSS aims to open science to young researchers with innovative ideas, provide researchers with flexible career opportunities and improve the way in which research is conducted. The most important measures of SOMACROSS are summarised in figure 4 .

\section{CONCLUSION}

Our patient-centred focus on subjectively distressing somatic symptoms has the potential to enable increased visibility of somatic symptom burden across different 


\section{Science}

\section{INSIGHTS}

Risk factors and mechanisms

\section{CROSSVALIDATION}

Disease-specific and generic mechanisms

DEVELOPMENT

Mechanism-based interventions

\section{Clinical care}

\section{PREVENTION}

Early recognition through risk scores

\section{TREATMENT}

More targeted treatment by

addressing mechanisms of action

INTERDISCIPLINARITY

Better collaboration in patient care
Competence building

STRUCTURE

Collaboration through RU framework

MUTUAL LEARNING

Communication between projects and targeted training

\section{EARLY CAREER}

Fostering research careers within $\mathrm{RU}$

Figure 4 Steps forward through the SOMACROSS research unit. RU, research unit.

medical specialties. SOMACROSS will enhance the relevance of each individual project by integrating knowledge about individual risk factors and mechanisms of PSS into joint analyses and publications. While we also anticipate challenges regarding comparability, transferability, and complexity of such a translational approach, we expect to gain insights on PSS that could not be reached without this collaboration. Our results will inform the development of mechanism-based tailored interventions, and in the long term, SOMACROSS will enable the translation of cutting-edge scientific knowledge into clinical practice by providing clinicians with evidence-based prevention and treatment options.

\section{Author affiliations}

${ }^{1}$ Department of Psychosomatic Medicine and Psychotherapy, University Medical

Center Hamburg-Eppendorf, Hamburg, Germany

${ }^{2}$ Department of Gastroenterology, Israelitic Hospital, Hamburg, Germany

${ }^{3}$ Research Group on Health Psychology, University of Leuven, Leuven, Belgium

${ }^{4}$ III. Department of Medicine, University Medical Center Hamburg-Eppendorf, Hamburg, Germany

${ }^{5}$ Medical Sociology, University Medical Center Hamburg-Eppendorf, Hamburg, Germany

${ }^{6}$ I. Department of Medicine, University Medical Center Hamburg-Eppendorf, Hamburg, Germany

${ }^{7}$ Department of Psychology, Helmut-Schmidt-University/University of the Armed Forces Hamburg, Hamburg, Germany

${ }^{8}$ Institute of Systems Neuroscience, University Medical Center Hamburg-Eppendorf, Hamburg, Germany

${ }^{9}$ Department of Psychosomatic Medicine and Psychotherapy, University Medical Center Münster, Münster, Germany

${ }^{10}$ Department of Dermatology and Venerology, University Medical Center HamburgEppendorf, Hamburg, Germany

${ }^{11}$ Martin Zeitz Center for Rare Diseases, University Medical Center Hamburg-

Eppendorf, Hamburg, Germany

${ }^{12}$ Department of Dermatology, Medical University Center Münster, Münster, Germany

${ }^{13}$ Institute of Medical Biometry and Epidemiology, University Medical Center Hamburg-Eppendorf, Hamburg, Germany

${ }^{14}$ Department of Psychology, Medical School Hamburg, Hamburg, Germany

Acknowledgements We would like to thank Professor Dr Paul Enck, PhD, University Hospital, Tübingen, Germany, Professor Dr Peter Henningsen, MD, Technical University Hospital, Munich, Germany, Professor Dr Uwe Koch-Gromus,
MD, PhD, University Medical Centre Hamburg-Eppendorf, Germany and Professor Dr Judith Rosmalen, PhD, University Medical Centre Groningen, the Netherlands, for their continuous and extremely helpful support during the application process for the SOMACROSS research unit. We are also very grateful to Professor Simone Kühn, PhD and Professor Jürgen Gallinat, MD, University Medical Centre HamburgEppendorf, Germany, for their valuable contributions to previous versions of the SOMACROSS research proposal. Finally, we would like to thank Dr Kerstin Maehder, $\mathrm{PhD}$, for her critical review of this study protocol.

Contributors $B L$ is the speaker of the SOMACROSS research unit. OVdB is a Mercator Fellow of this research unit. VA, TBH, OvdK, BL, AWL, YN, GS, SWS, CS, MS-M, SS, AT and AZ lead the individual SOMACROSS projects. AZ and EV provide statistical expertise to all projects of the research unit. BL drafted the first version of the protocol, MS-M and AT contributed individual parts of the protocol. All authors VA, OVdB, TBH, OvdK, BL, AWL, YN, GS, SWS, CS, MS-M, SS, AT, EV and AZ contributed to the refinement of the study protocol, read and approved the final version. MS-M and AT shared last authorship.

Funding The research unit 5211 (RU 5211) "Persistent SOMAtic symptoms ACROSS diseases: from risk factors to modification (SOMACROSS)" is funded by the German Research Foundation (Deutsche Forschungsgemeinschaft, DFG). The DFG project number for the coordination project is 445297796 (speaker: Professor Bernd Löwe, MD); see also https://gepris.dfg.de/gepris/projekt/445297796.

Competing interests None declared.

Patient and public involvement Patients and/or the public were involved in the design, or conduct, or reporting, or dissemination plans of this research. Refer to the Methods section for further details.

Patient consent for publication Consent obtained directly from patient(s)

Provenance and peer review Not commissioned; peer-reviewed for ethical and funding approval prior to submission.

Open access This is an open access article distributed in accordance with the Creative Commons Attribution Non Commercial (CC BY-NC 4.0) license, which permits others to distribute, remix, adapt, build upon this work non-commercially, and license their derivative works on different terms, provided the original work is properly cited, appropriate credit is given, any changes made indicated, and the use is non-commercial. See: http://creativecommons.org/licenses/by-nc/4.0/.

ORCID iD

Bernd Löwe http://orcid.org/0000-0003-4220-3378

\section{REFERENCES}

1 Kohlmann S, Gierk B, Hümmelgen M, et al. Somatic symptoms in patients with coronary heart disease: prevalence, risk factors, and quality of life. JAMA Intern Med 2013;173:1469-71.

2 Löwe B, Spitzer RL, Williams JBW, et al. Depression, anxiety and somatization in primary care: syndrome overlap and functional impairment. Gen Hosp Psychiatry 2008;30:191-9. 
3 Henningsen P, Gündel H, Kop WJ, et al. Persistent physical symptoms as perceptual dysregulation: a Neuropsychobehavioral model and its clinical implications. Psychosom Med 2018;80:422-31.

4 Klaus K, Rief W, Brähler E, et al. The distinction between "medically unexplained" and "medically explained" in the context of somatoform disorders. Int J Behav Med 2013;20:161-71.

5 Joustra ML, Janssens KAM, Bültmann U, et al. Functional limitations in functional somatic syndromes and well-defined medical diseases. results from the general population cohort lifelines. J Psychosom Res 2015;79:94-9.

6 Kohlmann S, Gierk B, Murray AM, et al. Base rates of depressive symptoms in patients with coronary heart disease: an individual symptom analysis. PLoS One 2016;11:e0156167.

7 Kroenke K, Zhong X, Theobald D, et al. Somatic symptoms in patients with cancer experiencing pain or depression: prevalence, disability, and health care use. Arch Intern Med 2010;170:1686-94.

8 Kroenke K. A practical and evidence-based approach to common symptoms: a narrative review. Ann Intern Med 2014;161:579-86.

9 World Health Organization (WHO). International classification of disease, ICD-11, 2020. Available: https://icd.who.int/en2019

10 Hinz A, Ernst J, Glaesmer H, et al. Frequency of somatic symptoms in the general population: normative values for the patient health Questionnaire-15 (PHQ-15). J Psychosom Res 2017;96:27-31.

11 Kroenke K. Patients presenting with somatic complaints: epidemiology, psychiatric comorbidity and management. Int $J$ Methods Psychiatr Res 2003;12:34-43.

12 Acevedo-Mesa A, Tendeiro JN, Roest A, et al. Improving the measurement of functional somatic symptoms with item response theory. Assessment 2021;28:1960-1970.

13 Steinbrecher N, Koerber S, Frieser D, et al. The prevalence of medically unexplained symptoms in primary care. Psychosomatics 2011;52:263-71.

14 Schappert SM, Rechtsteiner EA. Ambulatory medical care utilization estimates for 2007. Vital and health statistics Series 13, Data from the National Health Survey; 2011: 1-38.

15 Wiborg JF, Gieseler D, Fabisch AB, et al. Suicidality in primary care patients with somatoform disorders. Psychosom Med 2013;75:800-6.

16 Jordan P, Shedden-Mora MC, Löwe B. Predicting suicidal ideation in primary care: an approach to identify easily assessable key variables. Gen Hosp Psychiatry 2018;51:106-11.

17 Konnopka A, Kaufmann C, König $\mathrm{H}-\mathrm{H}$, et al. Association of costs with somatic symptom severity in patients with medically unexplained symptoms. J Psychosom Res 2013;75:370-5.

18 Wortman MSH, Lokkerbol J, van der Wouden JC, et al. CostEffectiveness of interventions for medically unexplained symptoms: a systematic review. PLoS One 2018;13:e0205278.

19 Henningsen P, Zipfel S, Sattel H, et al. Management of functional somatic syndromes and bodily distress. Psychother Psychosom 2018;87:12-31.

20 Aaron LA, Buchwald D. A review of the evidence for overlap among unexplained clinical conditions. Ann Intern Med 2001;134:868-81.

21 Burton C, Fink P, Henningsen P, et al. Functional somatic disorders: discussion paper for a new common classification for research and clinical use. BMC Med 2020;18:34

22 American Psychiatric Association (APA). Diagnostic and statistical manual of mental disorders. 4th ed. Washington DC: American Psychiatric Association, 1994

23 Dilling $\mathrm{H}$, Mombour W, Schmidt M. Weltgesundheitsorganisation: Internationale Klassifikation psychischer Störungen. ICD-10 Kapitel V (F). Klinisch-diagnostische Leitlinien. 3. Auflage. Bern, Swiss: Huber, 1999.

24 Picariello F, Ali S, Moss-Morris R, et al. The most popular terms for medically unexplained symptoms: the views of CFS patients. $J$ Psychosom Res 2015;78:420-6.

25 Marks EM, Hunter MS. Medically unexplained symptoms: an acceptable term? Br J Pain 2015;9:109-14.

26 American Psychiatric Association (APA). Diagnostic and statistical manual of mental disorders. Fifth Edition. Arlington, VA: American Psychiatric Association, 2013.

27 Dimsdale JE, Creed F, Escobar J, et al. Somatic symptom disorder: an important change in DSM. J Psychosom Res 2013;75:223-8.

28 Juergens MC, Seekatz B, Moosdorf RG, et al. Illness beliefs before cardiac surgery predict disability, quality of life, and depression 3 months later. J Psychosom Res 2010;68:553-60.

29 Nestoriuc Y, von Blanckenburg P, Schuricht F, et al. Is it best to expect the worst? influence of patients' side-effect expectations on endocrine treatment outcome in a 2-year prospective clinical cohort study. Ann Oncol 2016;27:1909-15.
30 Löwe B, Lohse A, Andresen V, et al. The development of irritable bowel syndrome: a prospective community-based cohort study. Am J Gastroenterol 2016;111:1320-9.

31 Rief W, Shedden-Mora MC, Laferton JAC, et al. Preoperative optimization of patient expectations improves long-term outcome in heart surgery patients: results of the randomized controlled PSYHEART trial. BMC Med 2017;15:4.

32 Brown SA, Tyrer FC, Clarke AL, et al. Symptom burden in patients with chronic kidney disease not requiring renal replacement therapy. Clin Kidney J 2017; 10:788-96.

33 Almutary H, Bonner A, Douglas C. Symptom burden in chronic kidney disease: a review of recent literature. J Ren Care 2013;39:140-50.

34 Griffiths L, Jones DE. Pathogenesis of primary biliary cirrhosis and its fatigue. Dig Dis 2014;32:615-25.

35 Kumar S, Joshi R, Joge V. Do clinical symptoms and signs predict reduced renal function among hospitalized adults? Ann Med Health Sci Res 2013;3:492-7.

36 Chalder T, Patel M, James K, et al. Persistent physical symptoms reduction intervention: a system change and evaluation in secondary care (PRINCE secondary) - a CBT-based transdiagnostic approach: study protocol for a randomised controlled trial. BMC Psychiatry 2019;19:307.

37 Ballering AV, Bonvanie IJ, Olde Hartman TC, et al. Gender and sex independently associate with common somatic symptoms and lifetime prevalence of chronic disease. Soc Sci Med 2020;253:112968.

38 Borsook D, Youssef AM, Simons L, et al. When pain gets stuck: the evolution of pain chronification and treatment resistance. Pain 2018;159:2421-36.

39 Kirmayer LJ, Sartorius N. Cultural models and somatic syndromes. Psychosom Med 2007;69:832-40.

40 Afari N, Ahumada SM, Wright LJ, et al. Psychological trauma and functional somatic syndromes: a systematic review and metaanalysis. Psychosom Med 2014;76:2-11

41 Karatzias T, Howard R, Power K, et al. Organic vs. functional neurological disorders: the role of childhood psychological trauma. Child Abuse Negl 2017;63:1-6.

42 Borsini A, Hepgul N, Mondelli V, et al. Childhood stressors in the development of fatigue syndromes: a review of the past 20 years of research. Psychol Med 2014;44:1809-23.

43 Herzog JI, Schmahl C. Adverse childhood experiences and the consequences on neurobiological, psychosocial, and somatic conditions across the lifespan. Front Psychiatry 2018;9:420.

44 Claassen-van Dessel N, van der Wouden JC, Hoekstra T, et al. The 2-year course of medically unexplained physical symptoms (MUPS) in terms of symptom severity and functional status: results of the prospects cohort study. J Psychosom Res 2018;104:76-87.

45 Gillespie NA, Zhu G, Heath AC, et al. The genetic aetiology of somatic distress. Psychol Med 2000;30:1051-61.

46 Rief W, Martin A. How to use the new DSM-5 somatic symptom disorder diagnosis in research and practice: a critical evaluation and a proposal for modifications. Annu Rev Clin Psychol 2014;10:339-67.

47 Deary V, Chalder T, Sharpe M. The cognitive behavioural model of medically unexplained symptoms: a theoretical and empirical review. Clin Psychol Rev 2007;27:781-97.

48 Rief W, Barsky AJ. Psychobiological perspectives on somatoform disorders. Psychoneuroendocrinology 2005;30:996-1002.

49 Brown RJ. Psychological mechanisms of medically unexplained symptoms: an integrative conceptual model. Psychol Bull 2004;130:793-812.

50 Rief W, Broadbent E. Explaining medically unexplained symptomsmodels and mechanisms. Clin Psychol Rev 2007;27:821-41.

51 Barsky AJ, Wyshak G. Hypochondriasis and somatosensory amplification. Br J Psychiatry 1990;157:404-9.

52 Boersma K, Linton SJ. How does persistent pain develop? an analysis of the relationship between psychological variables, pain and function across stages of chronicity. Behav Res Ther 2005;43:1495-507

53 De Gucht V, Heiser W. Alexithymia and somatisation: quantitative review of the literature. J Psychosom Res 2003;54:425-34.

54 Picavet HSJ, Vlaeyen JWS, Schouten JSAG. Pain catastrophizing and kinesiophobia: predictors of chronic low back pain. Am J Epidemiol 2002;156:1028-34.

55 Vlaeyen JWS, Crombez G, Linton SJ. The fear-avoidance model of pain. Pain 2016;157:1588-9.

56 Boersma K, Linton S, Overmeer T, et al. Lowering fear-avoidance and enhancing function through exposure in vivo. A multiple baseline study across six patients with back pain. Pain 2004;108:8-16.

57 Löwe B, Gerloff C. Functional somatic symptoms across cultures: perceptual and health care issues. Psychosom Med 2018;80:412-5. 
58 Peters EMJ. Stressed skin?--a molecular psychosomatic update on stress-causes and effects in dermatologic diseases. J Dtsch Dermatol Ges 2016;14:233-52.

59 van Ravenzwaaij J, Olde Hartman T, van Ravesteijn $\mathrm{H}$, et al Explanatory models of medically unexplained symptoms: a qualitative analysis of the literature. Ment Health Fam Med 2010;7:223-31.

60 Barsky AJ, Saintfort R, Rogers MP, et al. Nonspecific medication side effects and the nocebo phenomenon. JAMA 2002;287:622-7.

61 Heim C, Ehlert U, Hellhammer DH. The potential role of hypocortisolism in the pathophysiology of stress-related bodily disorders. Psychoneuroendocrinology 2000;25:1-35.

62 Bjurstrom MF, Giron SE, Griffis CA. Cerebrospinal fluid cytokines and neurotrophic factors in human chronic pain populations: a comprehensive review. Pain Pract 2016;16:183-203.

63 van den Broeke EN. Central sensitization and pain hypersensitivity: some critical considerations. F1000Res 2018;7:1325.

64 Nagy-Szakal D, Williams BL, Mishra N, et al. Fecal metagenomic profiles in subgroups of patients with myalgic Encephalomyelitis/ Chronic fatigue syndrome. Microbiome 2017;5:44

65 Minerbi A, Gonzalez E, Brereton NJB, et al. Altered microbiome composition in individuals with fibromyalgia. Pain 2019;160:2589-602.

66 Laferton JAC, Kube T, Salzmann S, et al. Patients' expectations regarding medical treatment: a critical review of concepts and their assessment. Front Psychol 2017;8:233.

67 Petrie KJ, Rief W. Psychobiological mechanisms of placebo and nocebo effects: pathways to improve treatments and reduce side effects. Annu Rev Psychol 2019;70:599-625.

68 Enck P, Bingel U, Schedlowski M, et al. The placebo response in medicine: minimize, maximize or personalize? Nat Rev Drug Discov 2013;12:191-204.

69 Vase L, Vollert J, Finnerup NB, et al. Predictors of the placebo analgesia response in randomized controlled trials of chronic pain: a meta-analysis of the individual data from nine industrially sponsored trials. Pain 2015;156:1795-802.

70 Goffaux P, de Souza JB, Potvin S, et al. Pain relief through expectation supersedes descending inhibitory deficits in fibromyalgia patients. Pain 2009;145:18-23.
71 Nestoriuc $\mathrm{Y}$, Orav EJ, Liang MH, et al. Prediction of nonspecific side effects in rheumatoid arthritis patients by beliefs about medicines. Arthritis Care Res 2010;62:791-9.

72 Schmitz J, Müller M, Stork J, et al. Positive treatment Expectancies reduce clinical pain and perceived limitations in movement ability despite increased experimental pain: a randomized controlled trial on sham opioid infusion in patients with chronic back pain. Psychother Psychosom 2019;88:203-14.

73 Kube T, Glombiewski JA, Rief W. Using different expectation mechanisms to optimize treatment of patients with medical conditions: a systematic review. Psychosom Med 2018;80:535-43.

74 Ongaro G, Kaptchuk TJ. Symptom perception, placebo effects, and the Bayesian brain. Pain 2019;160:1-4

75 Laux G, Rosemann T, Körner T, et al. [Detailed data collection regarding the utilization of medical services, morbidity, course of illness and outcomes by episode-based documentation in general practices within the CONTENT project]. Gesundheitswesen 2007;69:284-91.

76 Kroenke K, Spitzer RL, Williams JBW. The PHQ-15: validity of a new measure for evaluating the severity of somatic symptoms. Psychosom Med 2002;64:258-66.

77 Kroenke K, Spitzer RL, Williams JBW, et al. The patient health questionnaire somatic, anxiety, and depressive symptom scales: a systematic review. Gen Hosp Psychiatry 2010;32:345-59.

78 Rief W, Burton C, Frostholm L, et al. Core outcome domains for clinical trials on somatic symptom disorder, bodily distress disorder, and functional somatic syndromes: European network on somatic symptom disorders recommendations. Psychosom Med 2017;79:1008-15.

79 Toussaint A, Hüsing P, Kohlmann S. Detecting DSM-5 somatic symptom disorder: criterion validity of the Patient Health Questionnaire-15 (PHQ-15) and the Somatic Symptom Scale-8 (SSS8) in combination with the Somatic Symptom Disorder - B Criteria Scale (SSD-12). Psychol Med 2020;50:324-33

80 Toussaint A, Murray AM, Voigt $\mathrm{K}$, et al. Development and validation of the somatic symptom Disorder-B criteria scale (SSD-12). Psychosom Med 2016;78:5-12.

81 Ji R-R, Nackley A, Huh Y, et al. Neuroinflammation and central sensitization in chronic and widespread pain. Anesthesiology 2018;129:343-366. 